\title{
AVALIAÇÃO DO ÍNDICE DE QUALIDADE DA ÁGUA (IQA) DOS POÇOS DO BAIRRO DO CALABAR E SEU ENTORNO, SALVADOR - BA
}

\section{TITLE: EVALUATION OF WATER QUALITY INDEX (IQA) OF CALABAR BAIRRO WELLS AND ITS SURROUNDINGS, SALVADOR - BA}

Cristiane Barbosa de Oliveira

Engenheira Sanitarista e Ambiental, Universidade Federal da Bahia - UFBA. (tianebaroli@hotmail.com)

Adriana Costa Ferreira

Doutora em Química Analítica, Universidade Federal da Bahia - UFBA. (adrianacf@ufba.br)

Submissão: 16 de Setembro de 2019

Aceite: 19 de Novembro de 2019

\section{Resumo}

O presente trabalho visa calcular e avaliar o Índice de Qualidade da Água (IQA) dos poços localizados no bairro do Calabar e seu entorno, Salvador, Bahia, Brasil. Foram coletadas amostras de água em oito poços no período chuvoso (primeira campanha) e no período seco (segunda campanha). Para o cálculo do IQA, foram determinados os seguintes parâmetros: Demanda Bioquímica de Oxigênio (DBO), Oxigênio Dissolvido (OD), $\mathrm{pH}$, fósforo total, temperatura, coliformes termotolerantes, sólidos totais, turbidez e nitrogênio total. Cada parâmetro foi determinado individualmente e os resultados foram avaliados segundo: a Portaria de Consolidação № 05/17 (Anexo XX, Portaria 2.914), uma vez que parte da população local utiliza a água para fins de consumo humano; Resolução CONAMA № 396/08 e; apesar de ser para mananciais superficiais, a Resolução CONAMA № 357/05 que foi utilizada para verificação dos limites máximos de alguns parâmetros importantes, que não constam nas legislações anteriormente citadas. Após a análise da água dos poços, foi possível verificar que os valores de IQA obtidos para estes poços variaram entre regular e bom; sendo que no período chuvoso os poços que foram considerados de boa qualidade tiveram classificação regular no período seco e o inverso ocorreu nos poços de qualidade regular. Assim, não se pode concluir que as águas destes poços podem ser utilizadas com segurança para fins de consumo humano, pois os resultados individuais de alguns parâmetros não estão em conformidade com a Portaria de Consolidação $n^{\circ}$ 05/17 e as Resoluções CONAMA 357/05 e 396/08.

Palavras-Chave: Poços, IQA, Salvador.

\section{Abstract}

The present work aims to analyze the Water Quality Index (WQI) of the wells located in the Calabar neighborhood and its surroundings, Salvador, Bahia, Brazil. Water samples were collected in eight wells, with rainy season (first season) and dry season in (second season). To calculate the WQI the following parameters were determined: Biochemical Oxygen Demand (BOD), Dissolved Oxygen (OD), pH, total phosphorus, temperature, thermotolerant coliforms, total solids, turbidity and total nitrogen. Each parameter was analyzed based on the results and verified according to Ordinance of Consolidation No. 05/17 (former Ordinance 2.914), CONAMA Resolution No. 396/08 and, despite being applicable to surface problems, CONAMA No. 357/05 was used for there insertion of the ceilings of some important parameters, which are not included in legislations previously mentioned. After analyzing the water from the wells, it was found that the IQA values obtained for these wells ranged from regular to good; in the rainy season, wells that were considered of good quality had a regular classification in the dry season and the opposite occurred in wells of regular quality. Thus, it is not possible to conclude that the systems can be used safely, since the indicators of some parameters are not in conformity with the Ordinance of Consolidation $n{ }^{\circ} 05 / 17$ and the Resolutions CONAMA 357/05 and 396/08.

Keywords: Wells, WQI, Salvador. 


\section{INTRODUÇÃO}

A água é um elemento indispensável para os seres vivos, pois permite manter as funções vitais do organismo. Água limpa e de fácil acesso é importante para a saúde pública, seja ela usada para beber, para uso doméstico, para produzir alimentos ou para fins recreativos (OMS, 2018).

A escassez de água já afeta todos os continentes. O uso de água tem crescido globalmente, devido ao aumento populacional de mais do que o dobro em relação ao século passado, o que tem gerado um número crescente de regiões que está atingindo o limite no qual os serviços de água podem ser fornecidos de forma sustentável, especialmente em regiões áridas (ONU, 2018).

De acordo com o Ministério do Meio Ambiente (2018), o aumento da demanda por água é consequência direta do crescimento populacional e da ampliação dos níveis de consumo per capita, e tais fatores aumentam a pressão sobre os mananciais de abastecimento. Entre as situações que causam degradação das áreas de mananciais, podem ser destacadas: ocupação desordenada do solo, em especial áreas vulneráveis, como as Áreas de Proteção Permanentes (APP); práticas inadequadas de uso do solo e da água; falta de infraestrutura de saneamento (precariedade nos sistemas de esgotamento sanitário, manejo de águas pluviais e resíduos sólidos); superexploração dos recursos hídricos; remoção da cobertura vegetal; erosão e assoreamento de rios e córregos; e atividades industriais que se desenvolvem descumprindo a legislação ambiental (MMA, 2018).

Salvador é abastecida por vários mananciais fora da cidade. Segundo a Agência Nacional de Águas (ANA, 2010), Salvador é abastecida principalmente pelos rios Paraguaçu, localizado na região Centro - Oeste da Bahia, Ipitanga e o Joanes, na Região Metropolitana de Salvador (RMS). Os mananciais dentro da cidade não têm mais condições de fornecer água para a população devido ao alto grau de degradação. Um dos mananciais que abastecia Salvador era o Rio do Cobre, na região do Subúrbio Ferroviário.

Segundo estimativa do Censo de 2010 do Instituto Brasileiro de Geografia e Estatística, Salvador teria uma população, no ano de 2018, de 2.857.329 habitantes (IBGE, 2018). De acordo com o Sistema Nacional de Informações sobre
Saneamento (SNIS, 2016), a partir de dados de janeiro de 2016, a população atendida com abastecimento de água é de 2.660 .120 habitantes, ou seja, 93\%, se a população de 2018 fosse exatamente a estimada pelo IBGE. O déficit no abastecimento geralmente recai em áreas periféricas, onde são limitados não só o abastecimento de água, como também esgotamento sanitário, drenagem de águas pluviais e coleta de resíduos sólidos. O acesso difícil à água faz as pessoas recorrerem às soluções alternativas. De acordo com o Sistema de Informação Municipal de Salvador (SIM, 2018), com dados compilados do IBGE, o tipo de abastecimento de água nos domicílios particulares em Salvador, conforme os Censos de 1991, 2000 e 2010, mudou no decorrer dos anos, como pode ser visto na Tabela 1. Verifica-se que, com o aumento da cobertura da rede de abastecimento de água, ocorre uma redução na utilização de água de poço ou nascente, ou de outras formas.

Foi calculado e avaliado o Índice de Qualidade da Água dos poços existentes no bairro do Calabar e no seu entorno, na cidade de Salvador - Ba, nos períodos seco (agosto e setembro de 2018) e chuvoso (novembro de 2018). Além da avaliação dos limites de qualidade da água para os parâmetros estudados, de acordo com o Anexo XX da Portaria de Consolidação № 05/17 do Ministério da Saúde (2017) (potabilidade da água para consumo humano), as amostras também foram avaliadas segundo a Resolução CONAMA № 396/08 (classifica e enquadra as águas subterrâneas de acordo com os seus usos) e a Resolução CONAMA № 357/05 (classifica e enquadra os corpos hídricos superficiais e estabelece as condições e os padrões para lançamento de efluentes). Esta última Resolução terá utilidade aqui, apesar de se referir às águas superficiais, a título de comparação dos limites dos parâmetros que serão usados no cálculo do Índice de Qualidade da Água (IQA). Para as Resoluções CONAMA №396/08 e 357/05, os limites verificados serão de acordo com a classificação de águas doces na Classe 1 , as quais, além de outros usos, é a água que pode ser destinada ao consumo humano após o tratamento simplificado.

\section{Área de estudo}

O bairro do Calabar (Figura 1) está inserido 
na Bacia Hidrográfica de Ondina, que tem como limites a Bacia do Lucaia, ao Norte e Oeste, a Bacia Barra/Centenário, ao Sul, e o Oceano Atlântico, a Leste (SANTOS et al., 2010). Nesta bacia, também estão inseridos os bairros Alto das Pombas e Ondina, e as localidades de Jardim Apipema, Alto de Ondina e São Lázaro.

Tabela 1: Tipo de abastecimento de água em Salvador dos últimos Censos

\begin{tabular}{c|c|c|c}
\hline \multicolumn{4}{|c}{ Tipo de Abastecimento de Água nos Domicílios } \\
\hline Censo & Rede de Abastecimento & $\begin{array}{c}\text { Poço ou Nascente (na } \\
\text { propriedade) }\end{array}$ & Outra Forma \\
\hline 1991 & 445.862 & 10.081 & 22.122 \\
\hline 2000 & 628.851 & 5.622 & 16.820 \\
\hline 2010 & 849.244 & 2.603 & 6.843 \\
\hline
\end{tabular}

Fonte: Adaptada de SIM Salvador, 2018.

Figura 1: Mapa do bairro do Calabar

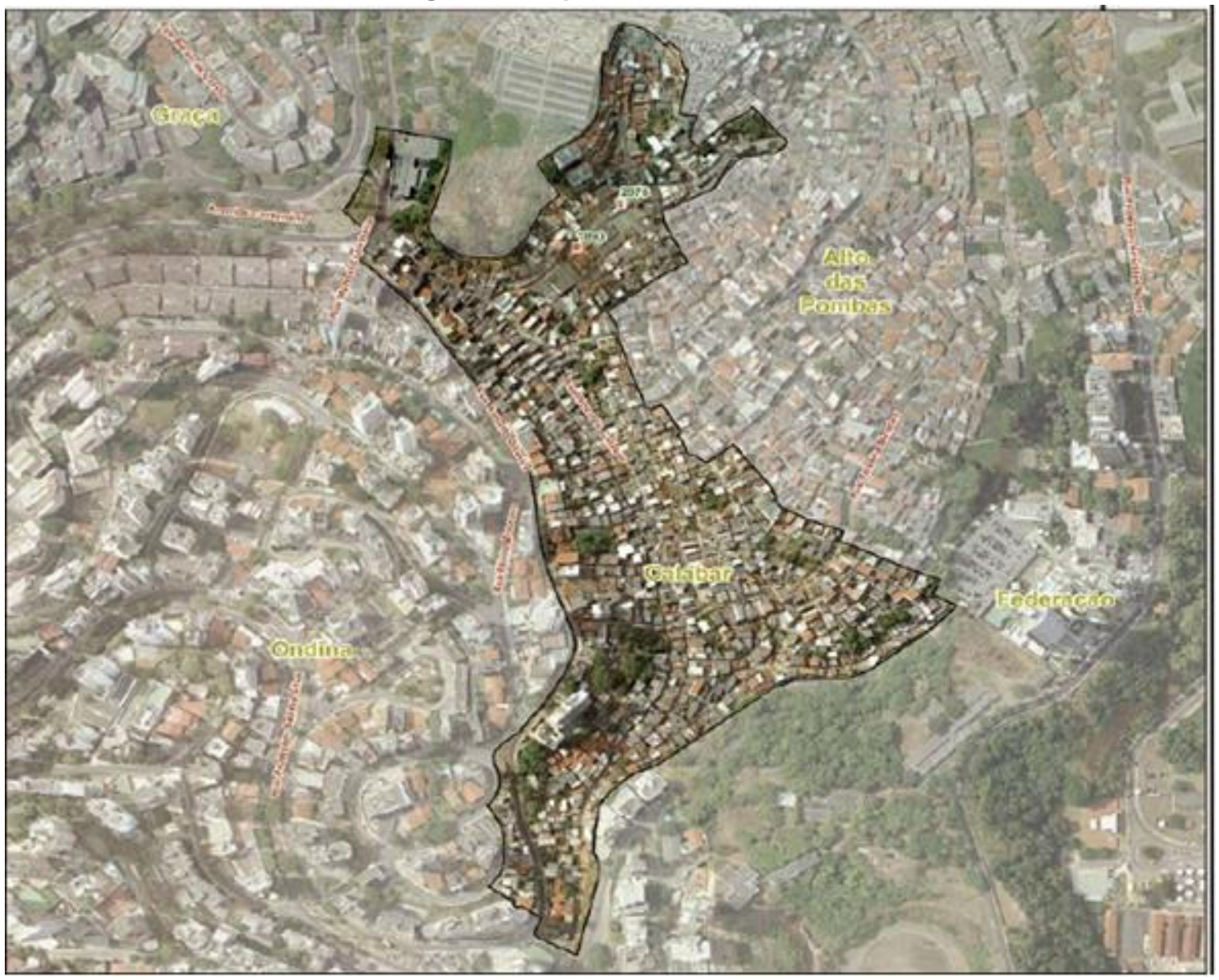

Fonte: Santos et al., 2010.

A rua principal, a Rua Nova do Calabar, estende-se entre as duas entradas do bairro: uma entrada por Ondina, que tem uma localidade conhecida como Largo do Camarão, e outra entrada pela Avenida Centenário, próxima ao bairro da Barra. A segunda rua mais importante é a paralela à Nova do Calabar, que se chama Rua do Riacho. Nessa localidade, corre o riacho que dá nome à rua, que foi transformado em galeria de águas pluviais. Também há uma região localizada atrás de um posto de saúde conhecido como Bomba, que, segundo informações de moradores, esta localidade tem esse nome porque há alguns anos atrás, para coletar água de um poço no local, era preciso utilizar uma bomba. O Calabar também está próximo ao 
Cemitério do Campo Santo e à Universidade Federal da Bahia.

A escolha dos poços no bairro do Calabar deveu-se a um fato ocorrido no ano de 2015. No mês de abril daquele ano, uma adutora de água tratada localizada na BR 324 foi atingida durante as obras do metrô, ocasionando o seu rompimento. Vários bairros em Salvador tiveram o seu abastecimento de água interrompido, inclusive o bairro do Calabar, que ficou quatro dias sem água. Além disso, a Empresa Baiana de Águas e Saneamento (EMBASA), quando realiza manutenção na rede, também suspende 0 abastecimento de água, geralmente por 24 horas. Assim, quando ocorrem estas interrupções no fornecimento de água, os moradores dos bairros do Calabar e Alto das Pombas utilizam essa água, mostrando a grande importância destes poços para a população.

Como a utilização de tais poços é para diversos fins, inclusive consumo humano, faz-se necessário que os responsáveis pelos poços e os moradores do Calabar e seu entorno tenham informações acerca da qualidade da água consumida, possibilitando que medidas preventivas sejam tomadas de acordo com o risco iminente.

\section{Índice de Qualidade da Água - IQA}

O Índice de Qualidade da Água - IQA foi criado em 1970, nos Estados Unidos, pela National Sanitation Foundation (NSF) (ANA, 2018). Foram propostas, inicialmente, 35 variáveis, contudo, somente o oxigênio dissolvido, coliformes fecais (termotolerantes), $\mathrm{pH}$, demanda bioquímica de oxigênio, nitrato, fosfato total, temperatura da água, turbidez e sólidos totais dissolvidos foram consideradas mais representativas (COSTA et al., 2012). Para cada variável, foi atribuído um peso (wi), de acordo com sua importância para a qualidade da água. $\mathrm{O}$ Quadro 1 mostra as variáveis utilizadas pela NSF.

Quadro 1: Variáveis para cálculo do IQA NSF

\begin{tabular}{|c|c|}
\hline Variável & Unidade \\
\hline Coliformes termotolerantes & UFC/100 mL \\
\hline DBO & $\mathrm{mg} / \mathrm{L} \mathrm{O} 2$ \\
\hline Fosfato total & $\mathrm{mg} / \mathrm{L} \mathrm{PO4}$ \\
\hline Nitratos & $\mathrm{mg} / \mathrm{L} \mathrm{PO3}$ \\
\hline Oxigênio dissolvido & $\%$ Saturação \\
\hline $\mathrm{pH}$ & - \\
\hline Sólidos totais dissolvidos & $\mathrm{mg} / \mathrm{L}$ \\
\hline Temperatura & ${ }^{\circ} \mathrm{C}$ \\
\hline Turbidez & $\mathrm{uT}$ ou NTU \\
\hline
\end{tabular}

Fonte: Adaptado de NSF apud Costa et al. (2012).

O IQA é calculado pelo produtório ponderado das qualidades de água correspondentes às variáveis que integram o índice (CETESB, 2014). Assim, utiliza-se a Equação 1:

Onde:

$$
\mathrm{IQA}=\prod_{i=1}^{n} q i^{\mathrm{in}}(1)
$$

IQA: Índice de Qualidade das Águas (entre 0 e 100)

n: número de variáveis utilizadas no cálculo do IQA

qi: qualidade do i-ésimo parâmetro (entre 0 e 100) obtido com a curva média específica de qualidade; os valores de qi são obtidos a partir da curva média de cada parâmetro

wi: peso que corresponde ao i-ésimo parâmetro, em função da sua importância para qualidade da água (entre 0 e 1), sendo expresso pela Equação 2.

$$
\sum_{i=1}^{n} w i=1
$$

A partir do IQA-NSF, em 1975, a Companhia Ambiental do Estado de São Paulo (CETESB, 2018) adaptou e desenvolveu o IQA, objetivando analisar a qualidade da água para abastecimento 
público. Mesmo considerando-se esse fim específico, 0 índice não contempla outras variáveis, como metais pesados, compostos orgânicos com potencial mutagênico, substâncias que afetam as propriedades organolépticas da água, número de células de cianobactérias e o potencial de formação de trihalometanos das águas de um manancial (CETESB, 2014). O IQA adaptado pela CETESB utiliza os parâmetros Nitrogênio Total, Fósforo Total, em vez de Nitrato e Fosfato, utilizados pela NSF.

O IQA resulta em níveis de qualidade que vão de uma escala entre muito ruim a excelente. O Quadro 2 mostra a classificação segundo o NSF e CETESB.

Existem outras adaptações para o IQA, diferindo nos parâmetros e objetivos de análise. Pode-se citar como exemplo o Índice de Qualidade da Água Bruta para Fins de Abastecimento Público (IAP), Índice de Qualidade de Água Subterrânea (IQAS), Índice de Toxidez, dentre outros.

De acordo com a CETESB (2014), as principais vantagens do índice são as facilidades de comunicação com o público leigo, o status maior do que as variáveis isoladas e o fato de representar uma média de diversas variáveis em um único número, combinando unidades de medidas diferentes em uma única unidade. No entanto, sua principal desvantagem consiste na perda de informação das variáveis individuais e da sua interação.

No trabalho em questão, o Índice de Qualidade da Água utilizado será o adaptado pela CETESB, uma vez que a população local e no seu entorno utiliza esta água quando há interrupção no abastecimento público por parte da concessionária Embasa.

\section{METODOLOGIA}

\section{Condições Climáticas}

As coletas foram realizadas em agosto e setembro de 2018, na primeira campanha, que seria caracterizada como período chuvoso, e novembro, quando, historicamente, o volume de chuvas na região é inferior, podendo considerá-lo como período seco (INMET, 2018). Na primeira campanha, choveu nos dias que antecederam o dia da coleta de amostras. Já na segunda campanha, não houve a ocorrência de chuvas nos dias anteriores à coleta, o que foi adequado para a caracterização dos dois períodos (seco e chuvoso) neste estudo.

Quadro 2: Níveis de classificação do IQA segundo NSF e CETESB

\begin{tabular}{|c|c|c|}
\hline IQA-NSF & IQA-CETESB & Classificação \\
\hline $0-25$ & $\leq 19$ & Péssima \\
\hline $26-50$ & $20-36$ & Ruim \\
\hline $51-70$ & $37-51$ & Regular \\
\hline $71-90$ & $52-79$ & Boa \\
\hline $91-100$ & $80-100$ & Excelente \\
\hline
\end{tabular}

\section{Caracterização dos poços}

Para a caracterização dos poços, foi realizada uma visita preliminar ao bairro, com 0 objetivo de estabelecer a localização exata dos poços. Assim, foi possível verificar que no bairro do Calabar existem onze poços, sendo dez ativos e um desativado, além de dois poços no entorno, totalizando treze poços. Destes, três poços são públicos, um localizado dentro do Calabar e os outros dois no entorno. Desta forma, observou-se que a maioria dos poços se localizava em propriedades particulares.
Os poços não foram construídos seguindo normas construtivas, como da ABNT NBR 12.244/06 - Construção de Poços para Captação de Água Subterrânea. Os poços foram escavados, com suas colunas revestidas artesanalmente, cujos fundos não têm qualquer proteção, ficando expostos à contaminação. Dos poços públicos, não foi possível encontrar informações precisas.

\section{Coleta das amostras}

Como a maioria dos poços estava em 
propriedades particulares, a coleta das amostras de água nestes locais foi realizada somente mediante autorização e disponibilidade dos moradores, nos dias estabelecidos para a atividade. As amostras também foram coletadas em três poços públicos, que não havia restrição ao acesso. Diante disto, só foi possível coletar amostras em oito poços. Assim, na primeira semana, as amostras foram coletadas em cinco pontos e, na outra, mais três poços foram amostrados, com o Sistema Universal Transverso de Mercator (UTM) descritas no Quadro 3:

A Figura 2 ilustra a localização dos poços, porém, não é possível visualizar o ponto 8 , que está localizado entre os pontos 2 e 7 , pois é muito próximo aos outros pontos, ficando oculto na Figura.

Figura 2: Localização dos poços

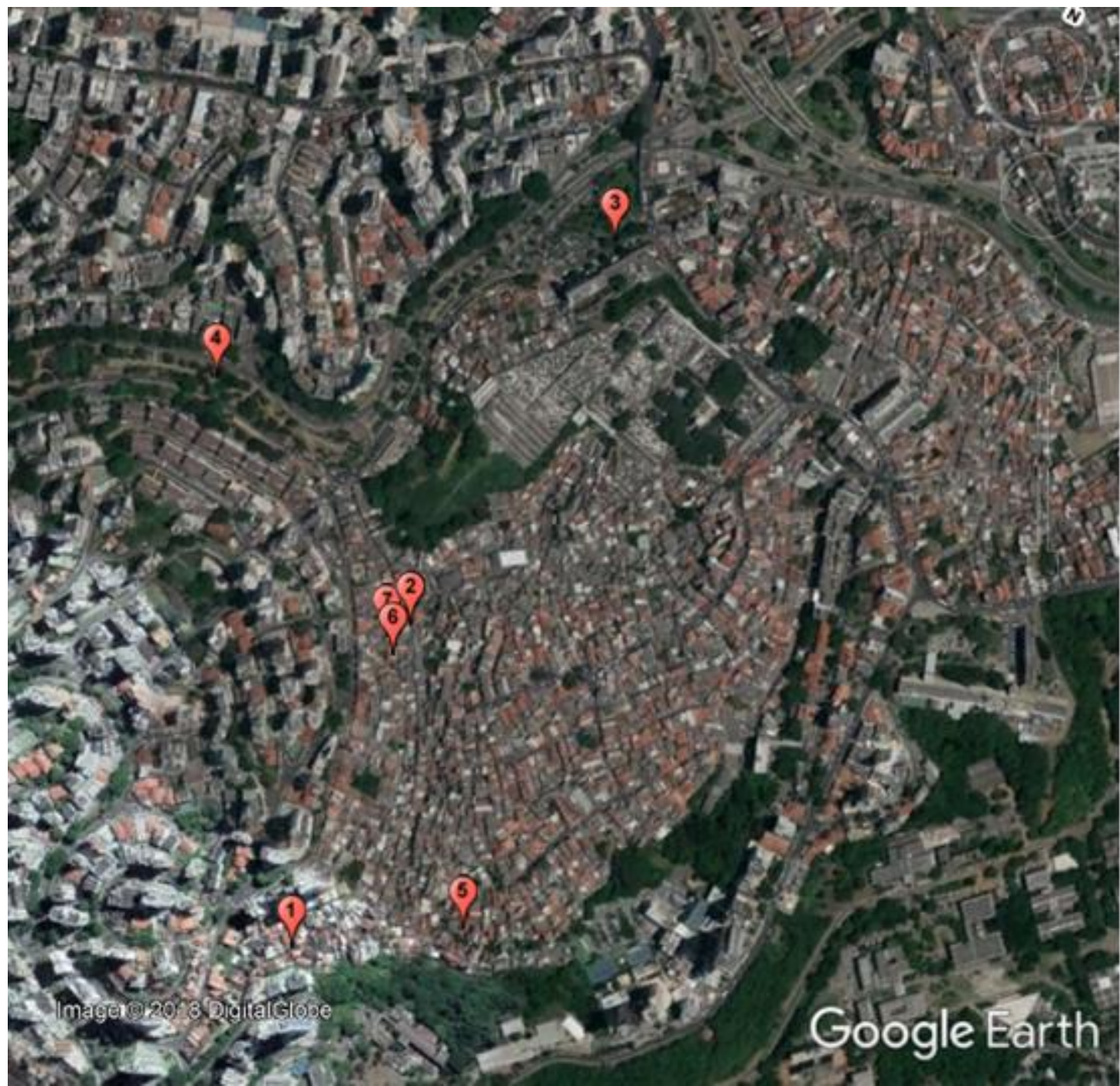

Fonte: Google Earth.

Todos os recipientes utilizados foram descontaminados previamente para evitar alterações nos resultados. Realizaram-se as etapas de coleta, acondicionamento e preservação das amostras de água de acordo com o estabelecido pelo Standard Methods of Examination of Water and Wastewater (APHA, 2012). As amostras permaneceram refrigeradas até 0 momento das respectivas análises. Estas foram efetuadas no laboratório do Departamento de Engenharia Sanitária e Ambiental (LABDEA) da Universidade Federal da Bahia.

$\mathrm{Na}$ maioria dos pontos de coleta, o espelho d'água dos poços era superficial, sendo possível a coleta manual. No ponto 1 , foi necessário captar a água por meio de bomba, pois se tratava de poço com grande profundidade. Aguardou-se cinco minutos de vazão de água para que a água 
contida na tubulação fosse descartada.

$\mathrm{Na}$ segunda campanha, as amostras foram coletadas somente em seis dos oito pontos amostrados na primeira campanha, sendo os seguintes: $1,2,4,5,7$ e 8 . No ponto 3 , não foi possível coletar amostra, pois o equipamento utilizado para transportar água do poço inferior para o superior havia sido furtada, prejudicando $o$ desempenho do trabalho da população local que fazia uso diariamente da água deste poço. A água superficial do poço 3 estava visivelmente suja, com o espelho d'água rebaixado, longe do alcance de coleta. No ponto 6 , a água não pôde ser coletada porque o responsável pelo poço não se encontrava.

O Quadro 4 mostra as técnicas e equipamentos empregados para cada parâmetro. No laboratório, as análises foram realizadas, como já mencionado, seguindo a metodologia analítica de referência do Standard Methods of Examination of Water and Wastewater (APHA, 2012).

Quadro 3: Coordenadas dos poços analisados

\begin{tabular}{|c|c|c|c|c|}
\hline PONTO & \multicolumn{2}{|c|}{ UTM } & TIPO & LOCAL \\
\hline & $\mathrm{X}$ & $\mathrm{Y}$ & & \\
\hline 1 & 552548,51 & 8562228,91 & Particular & Calabar \\
\hline 2 & 552490,68 & 8562612,4 & Particular & Calabar \\
\hline 3 & 552474,66 & 8563090,91 & Público & Entorno \\
\hline 4 & 552172,78 & 8562753,56 & Público & Entorno \\
\hline 5 & 552707,95 & 8562340,482 & Público & Calabar \\
\hline 6 & 552489,34 & 8562572,77 & Particular & Calabar \\
\hline 7 & 552473,1 & 8562586,26 & Particular & Calabar \\
\hline 8 & 552482,87 & 8562593,98 & Particular & Calabar \\
\hline
\end{tabular}

Fonte: Próprio autor.

Quadro 4: Técnicas e equipamentos empregados para cada parâmetro analisado

\begin{tabular}{|c|c|c|c|}
\hline Parâmetro & Técnica & Método & Equipamento/Vidaria \\
\hline $\mathrm{pH}$ & Potenciometria & SMEWW 4500-H B 22 $2^{\mathrm{a}}$ Ed. & PG 1800 GEHAKA \\
\hline Oxigênio dissolvido & Volumetria & 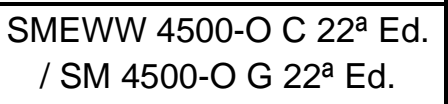 & Bureta graduada \\
\hline Turbidez & Turbidimetria & SMEWW 2130B 22를. & DL 350 DELL LAB \\
\hline DBO5 & Volumetria & SMEWW 5210B 22ª Ed. & Bureta graduada \\
\hline $\begin{array}{l}\text { Coliformes } \\
\text { termotolerantes }\end{array}$ & $\begin{array}{c}\text { Membrana Filtrante e } \\
\text { Estufa }\end{array}$ & $\begin{array}{l}\text { Membrana Filtrante SM } \\
\text { 9222D } 22^{2} \text { Ed. }\end{array}$ & - \\
\hline Fósforo total & Espectrofotometria & SMEWW 4500-P D 22ª Ed. & DR $6000 \mathrm{HACH}$ \\
\hline Temperatura & Termometria & - & Termômetro \\
\hline Sólidos totais & Gravimetria & SMEWW 2540B 22ª Ed. & $\begin{array}{l}\text { Balança AG } 200 \\
\text { GEHAKA }\end{array}$ \\
\hline Nitrogênio total & Espectrofotometria & KIT HACH LR / HR & DR $6000 \mathrm{HACH}$ \\
\hline
\end{tabular}

Fonte: Próprio autor. 


\section{RESULTADOS, ANÁLISE E DISCUSSÃO}

Os resultados para cada parâmetro e para 0 IQA (VON SPERLING, 2014) foram comparados para as duas campanhas realizadas. Não há resultados de análises das águas dos pontos $3 \mathrm{e}$ 6 para a segunda campanha, pois não se conseguiu realizar a amostragem nos respectivos poços.

\section{Parâmetros}

\section{- Temperatura}

A temperatura afeta um grande número de fatores biológicos e químicos nos corpos d'água, como a solubilidade de substâncias, gases, organismos e microorganismos, como os macroinvertebrados bentônicos (SCHILLER et al., 2019). A Figura 3 apresenta os dados de temperatura nas duas campanhas. A primeira campanha está representada pelo número 1 e a segunda campanha pelo número 2 .
Como observado na Figura 3 , as temperaturas variaram pouco entre os poços e nas duas campanhas. Em virtude de problemas técnicos, a temperatura para o ponto 5 da primeira campanha não pôde ser medida; no entanto, para viabilizar o cálculo do IQA deste ponto, foi necessário estimar a temperatura para verificar se haveria diferença no resultado. Assim, para o cálculo do IQA, simularam-se as temperaturas de $26^{\circ} \mathrm{C}, 27^{\circ} \mathrm{C}$ e $28^{\circ} \mathrm{C}$ para observar o seu efeito no cálculo. A temperatura tem muita importância na qualidade da água, já que a sua variação determina, dentre outras alterações, a velocidade das reações na água, a concentração de oxigênio dissolvido, a taxa de transferência de gases para a atmosfera, além da formação de subprodutos no tratamento da água (GUEZENNEC et al., 2017; SILVA et al., 2018). $\mathrm{Na}$ Portaria de Consolidação № 05/17, a temperatura é relevante na desinfecção da água, com a utilização de ozônio e na cloração.

Figura 3: Parâmetro Temperatura

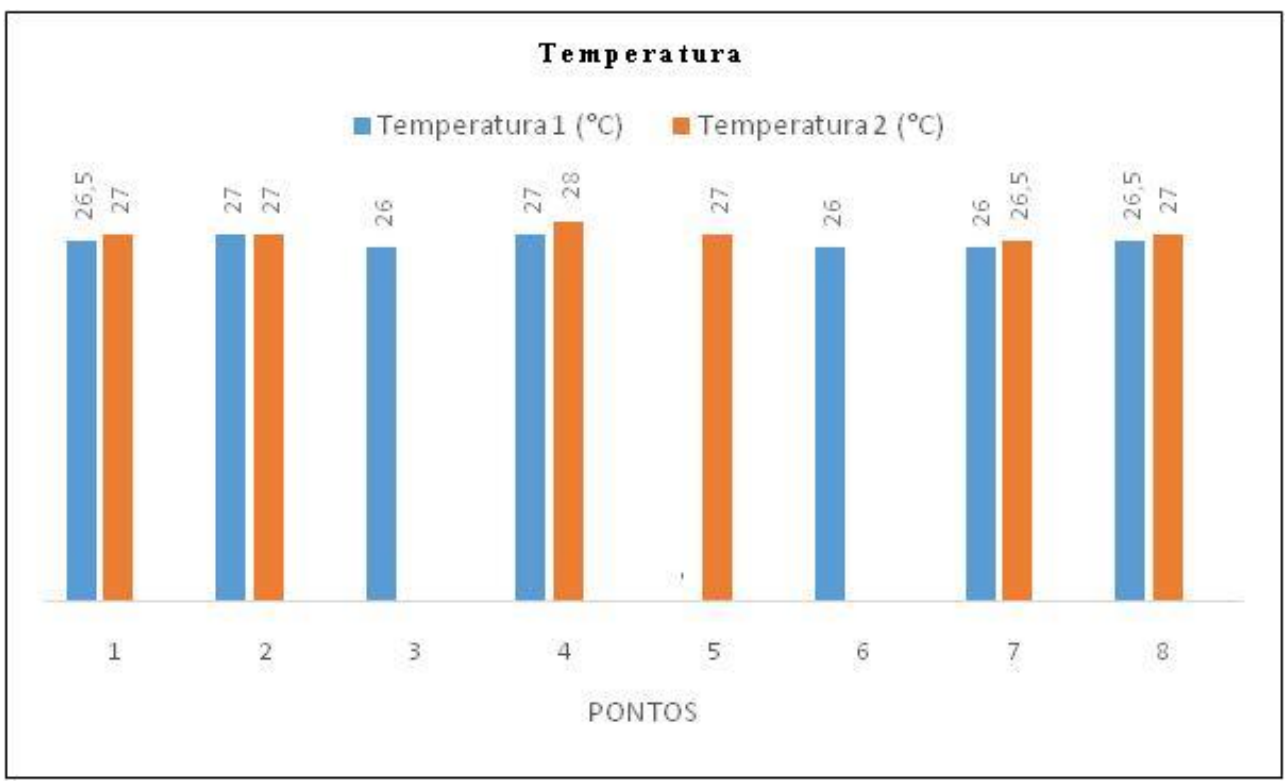

Fonte: Próprio autor.

- $\mathbf{p H}$

Como pode ser visto na Figura $4,0 \mathrm{pH}$ nos pontos amostrados variou entre 5,25 e 6,94 nas duas campanhas, indicando uma água levemente ácida. A Resolução CONAMA № 396/08 não informa qual seria o $\mathrm{pH}$ ideal, mas sinaliza que este parâmetro deve ser monitorado. A Portaria de Consolidação № 05/17 recomenda que, no sistema de distribuição de água para consumo humano, após o tratamento, o pH permaneça entre 6,0 e 9,5, não fazendo menção à água bruta. A Resolução CONAMA № 357/05 sinaliza que o pH deve variar entre 6,0 e 9,0, sendo que os pontos 2, 5 e 6 estão abaixo do que determina esta Resolução. Variações no pH interferem nas reações químicas e microbiológicas da água, assim como nas etapas do tratamento, como, por exemplo, na coagulação e desinfecção. Verificase também que no período chuvoso (primeira 
campanha) os valores de $\mathrm{pH}$ foram menores do que no período seco (segunda campanha) em todos os pontos, o que está de acordo com o observado por Rodríguez et al. (2019), os quais avaliaram a qualidade microbiológica da água de um riacho por meio de microrganismos indicadores.

Figura 4: Parâmetro pH

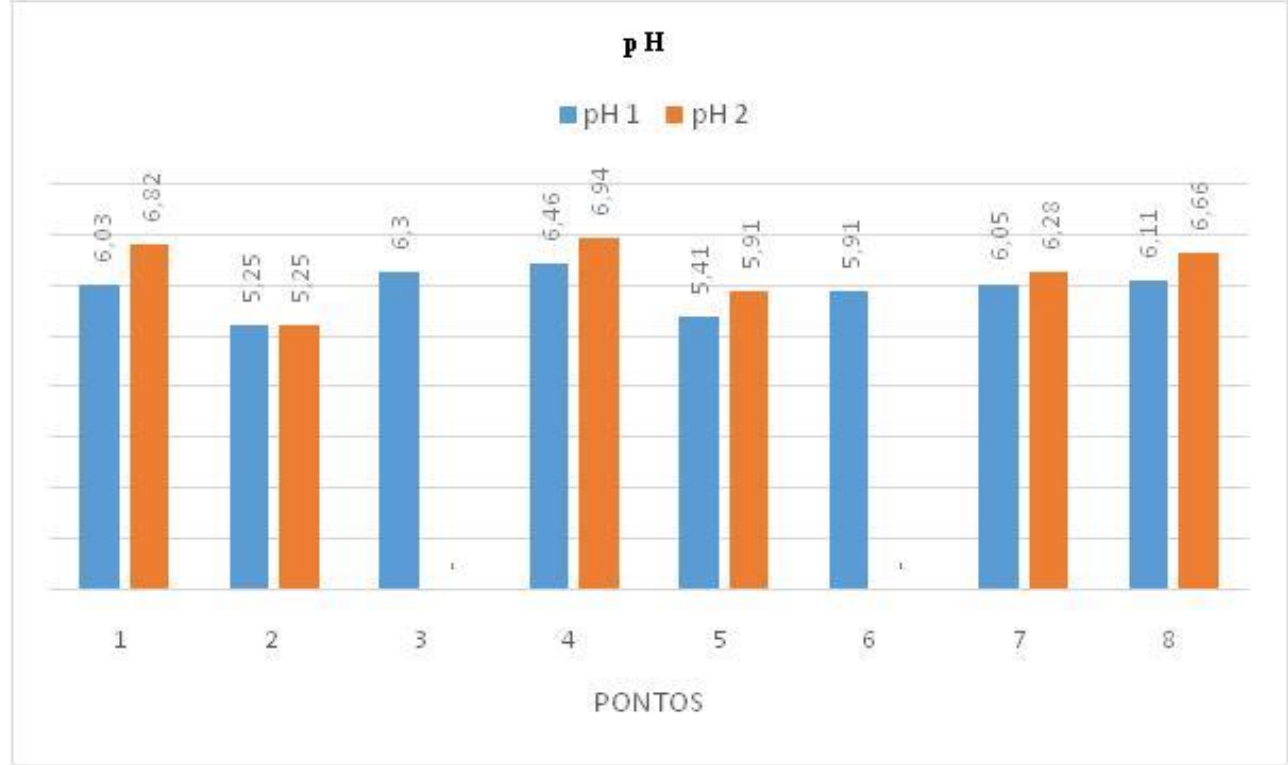

Fonte: Próprio autor.

\section{- Oxigênio Dissolvido}

Os valores de Oxigênio Dissolvido (OD) dos poços do Calabar, expressos na Figura 5, mostram que o maior valor se encontra no ponto 3. Neste ponto, a água chega por uma tubulação, e a altura desta tubulação para o espelho d'água gera turbulência, aumentando o oxigênio dissolvido na água. A Resolução CONAMA № 396/08 e a Portaria de Consolidação MS № 05/17 não informam sobre um limite de oxigênio dissolvido na água, pois esta concentração não é relevante em água para abastecimento. A Resolução CONAMA № 357/05 para águas doces classe 1 informa que o oxigênio dissolvido deve estar acima de $6 \mathrm{mg} / \mathrm{L} \mathrm{O}$, pois, para 0 ambiente aquático superficial, a quantidade deste parâmetro na água determina a sobrevivência dos organismos que lá vivem (ANIYIKAIYE et al., 2019; BUZELLI; CUNHA-SANTINO, 2013). Uma baixa concentração de oxigênio dissolvido na água pode indicar contaminação por efluentes domésticos, pois na decomposição da matéria orgânica os microrganismos consomem 0 oxigênio dissolvido presente na água. Uma das formas de consumo do oxigênio da água é através da oxidação da matéria orgânica carbonácea ou da oxidação da matéria orgânica nitrogenada.

\section{- Demanda Bioquímica de Oxigênio (DBO)}

A Demanda Bioquímica de Oxigênio (DBO) determina indiretamente a quantidade de matéria orgânica proveniente de efluentes domésticos na água, em que os microrganismos consomem o oxigênio dissolvido, sendo este um importante indicador da qualidade da água (ANIYIKAIYE et al., 2019).

Como se verifica na Figura 6, no ponto 1 , o valor de DBO5 foi mais alto nas duas campanhas. Nos pontos 6 e 7 também foram detectados índices de DBO5. Possivelmente, nestes pontos estejam ocorrendo contaminação por esgotos domésticos pelo fundo do poço, já que nenhum deles tem revestimento que possa proteger os poços. Somente a Resolução CONAMA № 357/05 tem limite máximo para a determinação de DBO5, sendo que, para águas doces classe 1, o máximo é de $3 \mathrm{mg} / \mathrm{L} \mathrm{O}_{2}$. Neste caso, somente 0 ponto 1 não atende ao limite máximo estabelecido por essa Resolução. Pode-se perceber que a baixa concentração 
de oxigênio dissolvido no ponto 1 está condizente com 0 alto valor de DBO5 neste mesmo ponto. Em relação aos outros pontos, a baixa concentração de oxigênio dissolvido pode estar relacionada com a oxidação da matéria orgânica nitrogenada ou a oxidação de outros compostos.

Figura 5: Parâmetro Oxigênio Dissolvido

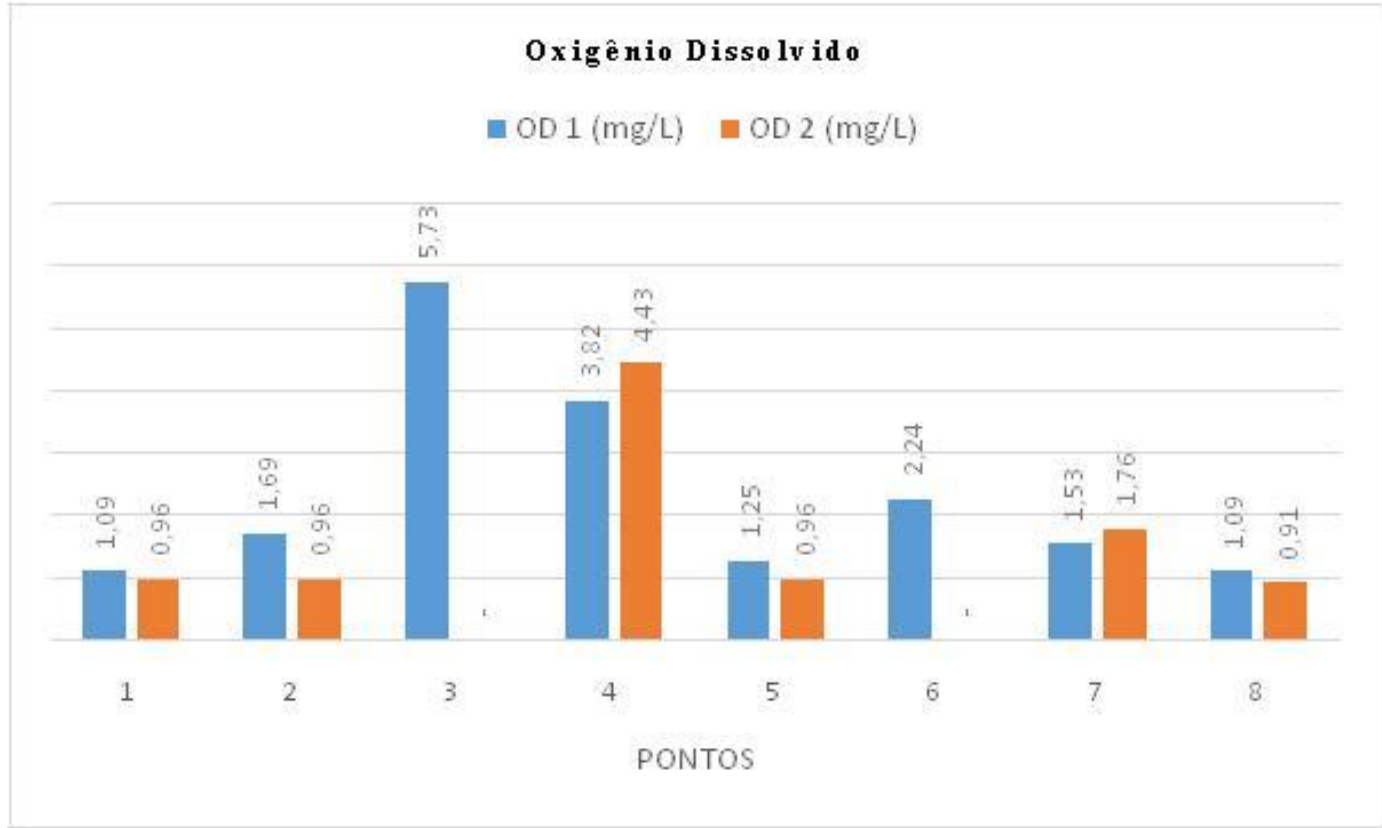

Fonte: Próprio autor.

Figura 6: Parâmetro DBO5

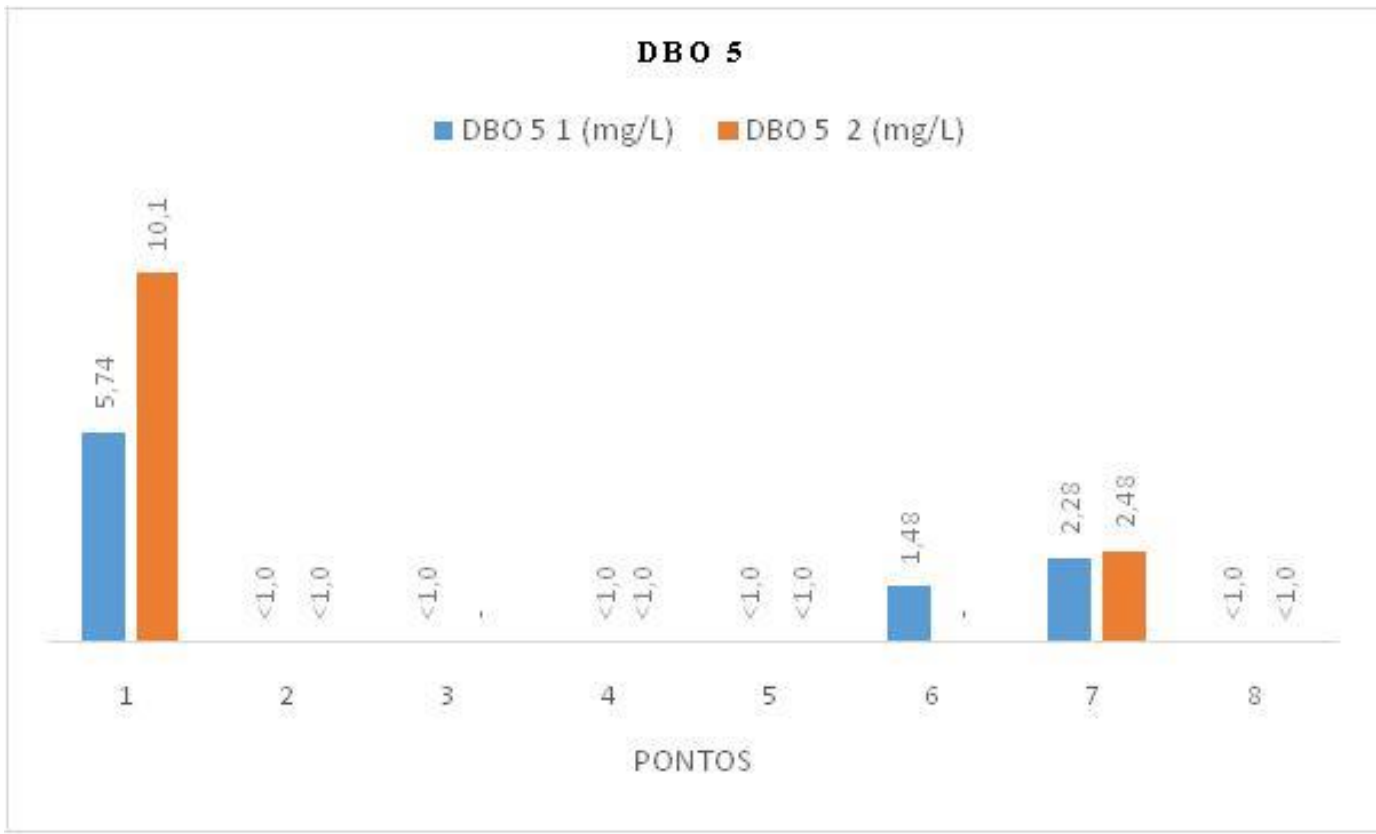

Fonte: Próprio autor.

- Turbidez

A turbidez na água é causada por partículas em suspensão ou matéria coloidal que obstrui a transmissão de luz através da água. Pode ser causada por matéria inorgânica ou orgânica ou por uma combinação dos dois (AVIGLIANO; 
SCHENONE, 2016). Como pode ser observada na Figura 7, a turbidez nos pontos amostrados variou entre 0,3 e 1,28 UNT, nas duas campanhas. A Resolução CONAMA № 396/08 afirma que este parâmetro deve ser monitorado, mas não informa um valor limite. A Portaria de Consolidação MS № 05/17 possui uma tabela padrão informando que, para águas subterrâneas cujo tratamento seja a desinfecção, a turbidez deve ter 1,0 UNT em $95 \%$ das amostras. A Resolução CONAMA № 357/05 informa que, para águas doces classe 1, o limite máximo para turbidez é no máximo de 40 UNT; assim, todos os pontos amostrados estão abaixo dos limites desta Resolução.

Figura 7: Parâmetro Turbidez

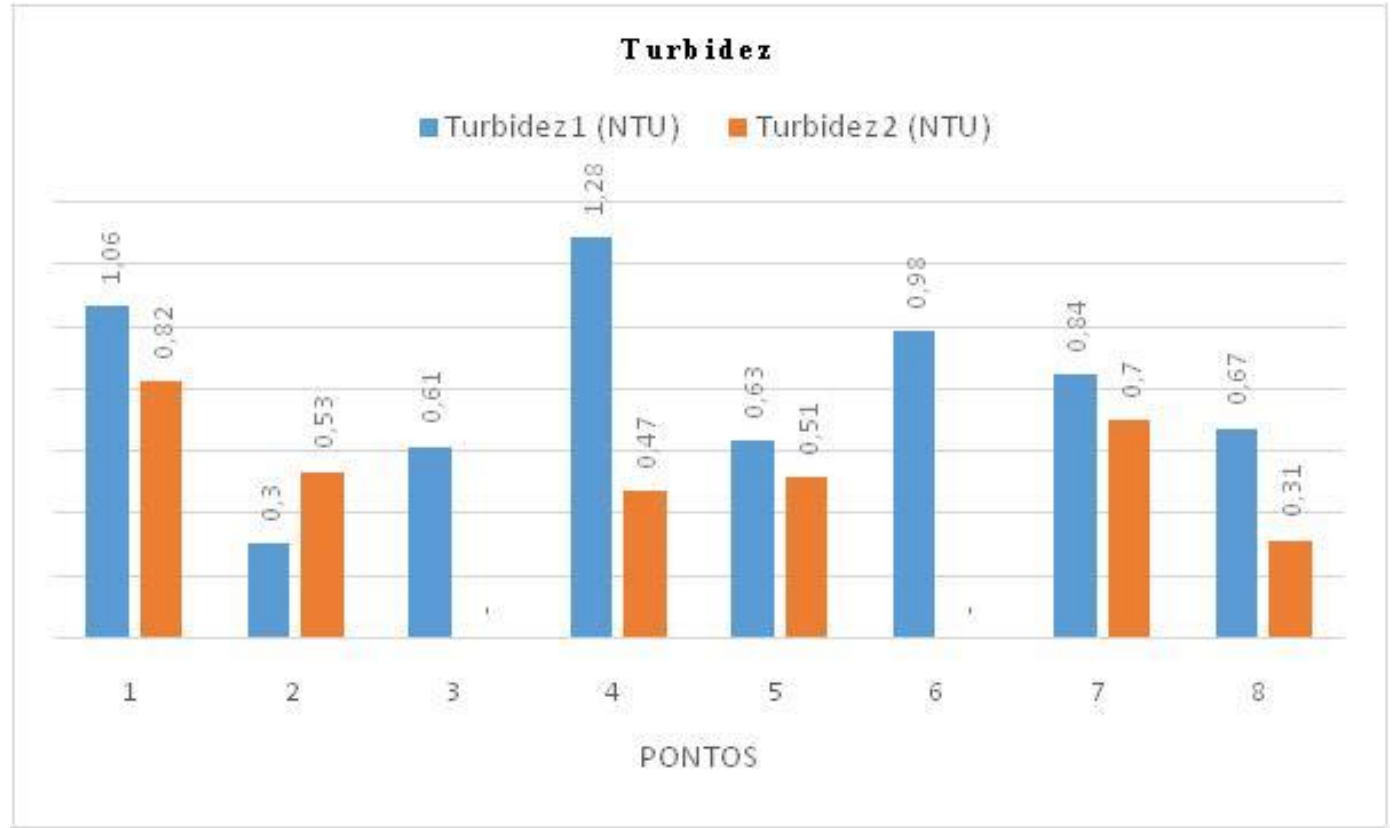

Fonte: Próprio autor.

\section{- Sólidos Totais}

O excesso de sólido pode afetar a comunidade aquática, alterando as condições de luminosidade das águas superficiais, interferindo no metabolismo de organismos autotróficos submersos, fotossíntese e, consequentemente, danificando outros organismos heterotróficos, dependendo do oxigênio dissolvido (BUZELLI; CUNHA-SANTINO, 2013). Como se pode observar na Figura 8, os resultados para sólidos totais de todos os pontos amostrados foram maiores na segunda campanha do que na primeira, mas todos estão abaixo do valor máximo permitido pela Portaria de Consolidação MS № 05/17 e pela Resolução CONAMA № 396/08, nas quais o valor máximo é de 1000 mg/L. Na Resolução CONAMA № 357/05, o limite máximo é até $500 \mathrm{mg} / \mathrm{L}$ para água doce classe 1 . Os pontos amostrados estão em conformidade com as referidas legislações.

Concentrações menores de sólidos em ambientes aquáticos nos meses de maior volume de água (primeira campanha) são comuns (SCHILLER et al., 2019); fato este associado ao efeito da diluição da água da chuva (CHRISTOFOLETTI et al., 2015).

\section{- Coliformes Termotolerantes}

Os coliformes termotolerantes são bactérias presentes no intestino de animais de sangue quente, inclusive humanos, sendo assim indicador de contaminação por fezes (RODRÍGUEZ et al, 2019).

$\mathrm{Na}$ Figura 9, é possível verificar que, na primeira campanha, o valor de coliformes termotolerantes do ponto 7 está bem acima dos valores encontrados nos outros pontos. $\mathrm{Na}$ segunda campanha, neste mesmo ponto, não foi detectada a presença dos coliformes termotolerantes. $\mathrm{Na}$ primeira campanha, o período era chuvoso, podendo ter ocorrido infiltração de água da chuva e esgoto no poço, o que gerou um acréscimo excessivo de contaminação por coliformes na água. Nos outros 
pontos, há uma diferença considerada permitida pelo método analítico, entre as duas campanhas. A Portaria de Consolidação MS № 5 não apresenta limite para coliformes termotolerantes, e sim de Escherichia coli, uma espécie de coliformes termotolerantes. A Resolução CONAMA №396/08 informa que as amostras de água devem ser ausentes de coliformes termotolerantes, e a Resolução CONAMA 357/05 estabelece um limite de 200 coliformes termotolerantes por 100 mililitros em $80 \%$ ou mais de pelo menos 6 amostras, coletadas durante o período de um ano. Desta forma, observa-se que os pontos 3, 4 e 7, em algum momento, excedem os limites para estas duas últimas legislações.

\section{Figura 8: Parâmetro Sólidos Totais}

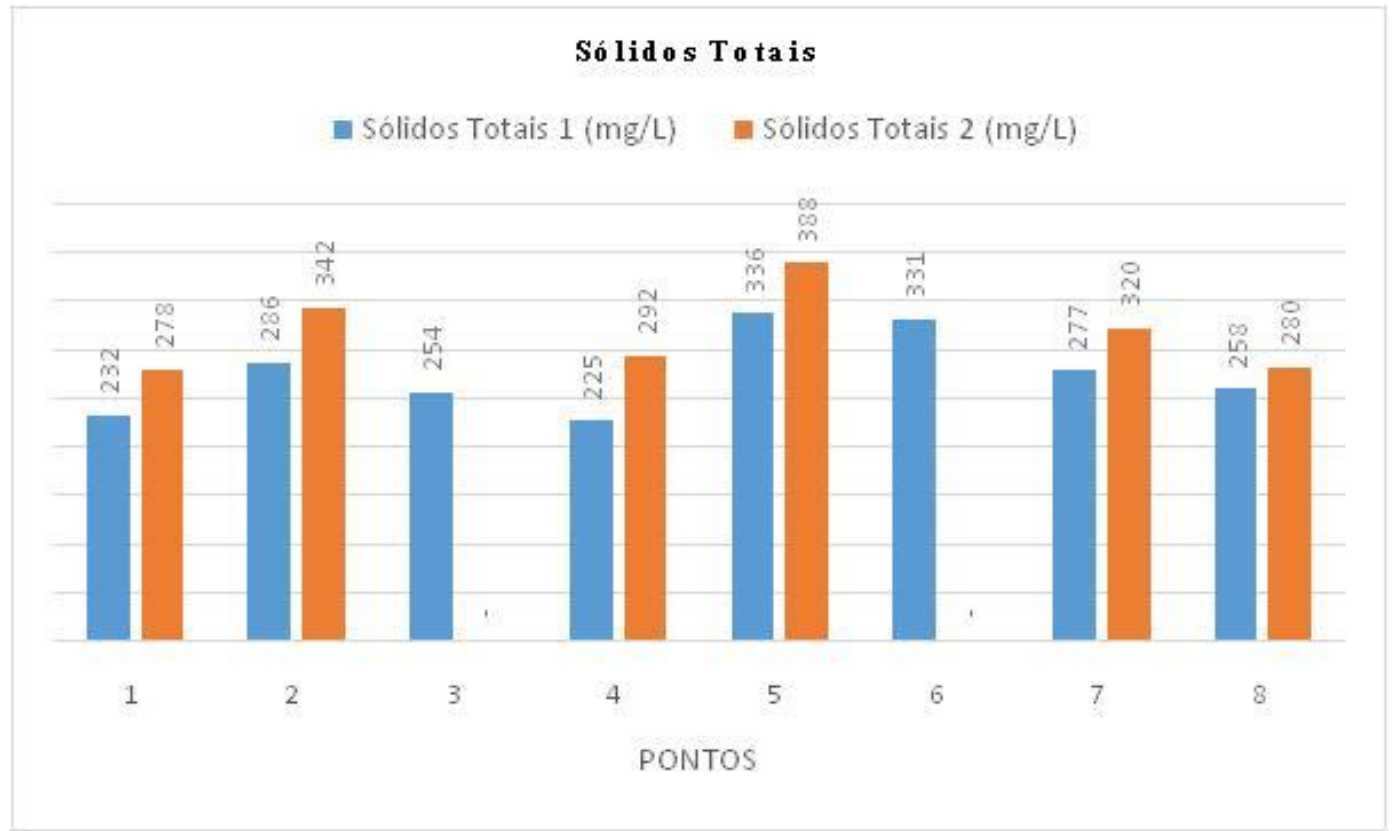

Fonte: Próprio autor.

Figura 9: Parâmetro Coliformes Termotolerantes

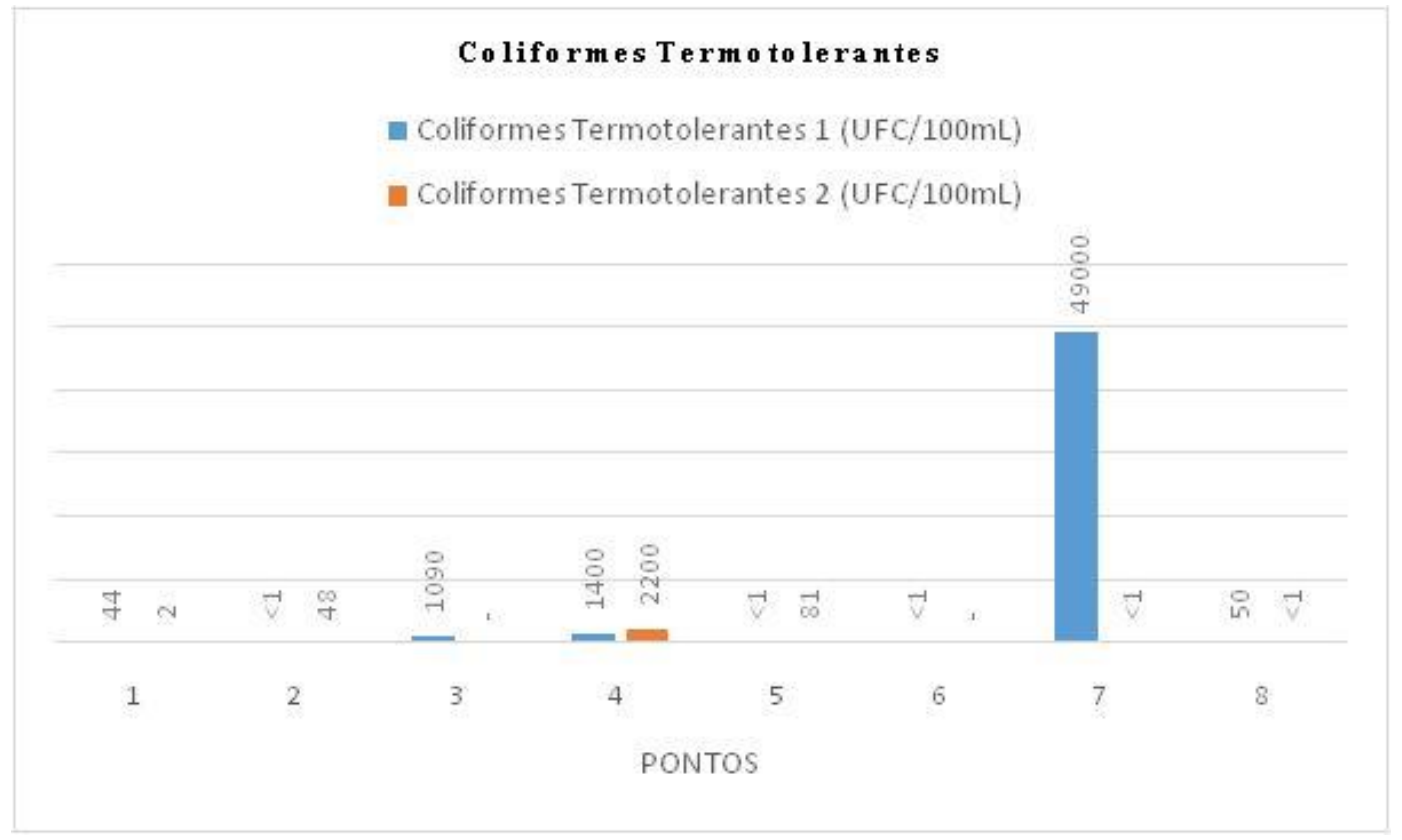

Fonte: Próprio autor. 


\section{- Fósforo Total}

A Figura 10 apresenta os resultados para fósforo total apenas da campanha 1, pois na segunda campanha todos os resultados dos pontos, onde foi possível realizar a coleta, foram $<0,1 \mathrm{mg} / \mathrm{L}$ de fósforo total.

O valor apresentado no ponto 3 , para a primeira campanha, pode ter sido devido a uma contaminação pontual por sabão ou detergente oriundos do momento em que os lavadores de carro coletam a água desse poço para utilizar na lavagem dos carros. A Resolução CONAMA № 396/08 e a Portaria de Consolidação MS № 05/17 não estabelecem um valor limite para fósforo total, e na Resolução CONAMA № 357/05 o limite máximo estabelecido é até $0,1 \mathrm{mg} / \mathrm{L} P$. Como a concentração de fósforo total excedeu o limite estabelecido pela Resolução CONAMA № $357 / 05$, o ponto 3 não está em conformidade com esta legislação. A importância do fósforo é devido ao fato de este elemento ser um nutriente essencial para o crescimento dos microrganismos responsáveis pela estabilização da matéria orgânica (VON SPERLING, 2014). Além disso, o fósforo favorece o crescimento de algas nos copos hídricos superficiais, aumentando a eutrofização, principalmente, de lagos (ZHA; MA; LU, 2018).

\section{- Compostos Nitrogenados}

A presença de compostos de nitrogênio, nos seus diferentes estados de oxidação, é indicativo de contaminação do aquífero e de possíveis condições higiênico-sanitárias insatisfatórias (ALABURDA; NISHIHARA, 1998). O nitrogênio pode ser encontrado na água nas seguintes formas:

- Nitrogênio orgânico, dissolvido ou particulado;

- Nitrogênio em sua forma molecular;

- Formas reduzidas nas condições anaeróbias: nitrogênio amoniacal, nitrogênio no estado gasoso, ou íon amônio; e

- As formas oxidadas Nitrito e Nitrato.

O nitrogênio, nos processos de conversão da amônia em nitrito e nitrato, implica no consumo de OD no corpo d'água receptor (VON SPERLING, 2014). De acordo com Von Sperling (2014), a determinação da forma predominante do nitrogênio pode fornecer indicações sobre o estágio da poluição eventualmente ocasionada por algum lançamento de esgotos. O nitrogênio estará nas formas orgânica ou amônio se a poluição for recente e, na forma de nitrato, se a poluição for mais antiga, sendo que as concentrações de nitrito serão menores na oxidação da amônia, pois é um produto instável.

Figura 10: Parâmetro Fósforo Total

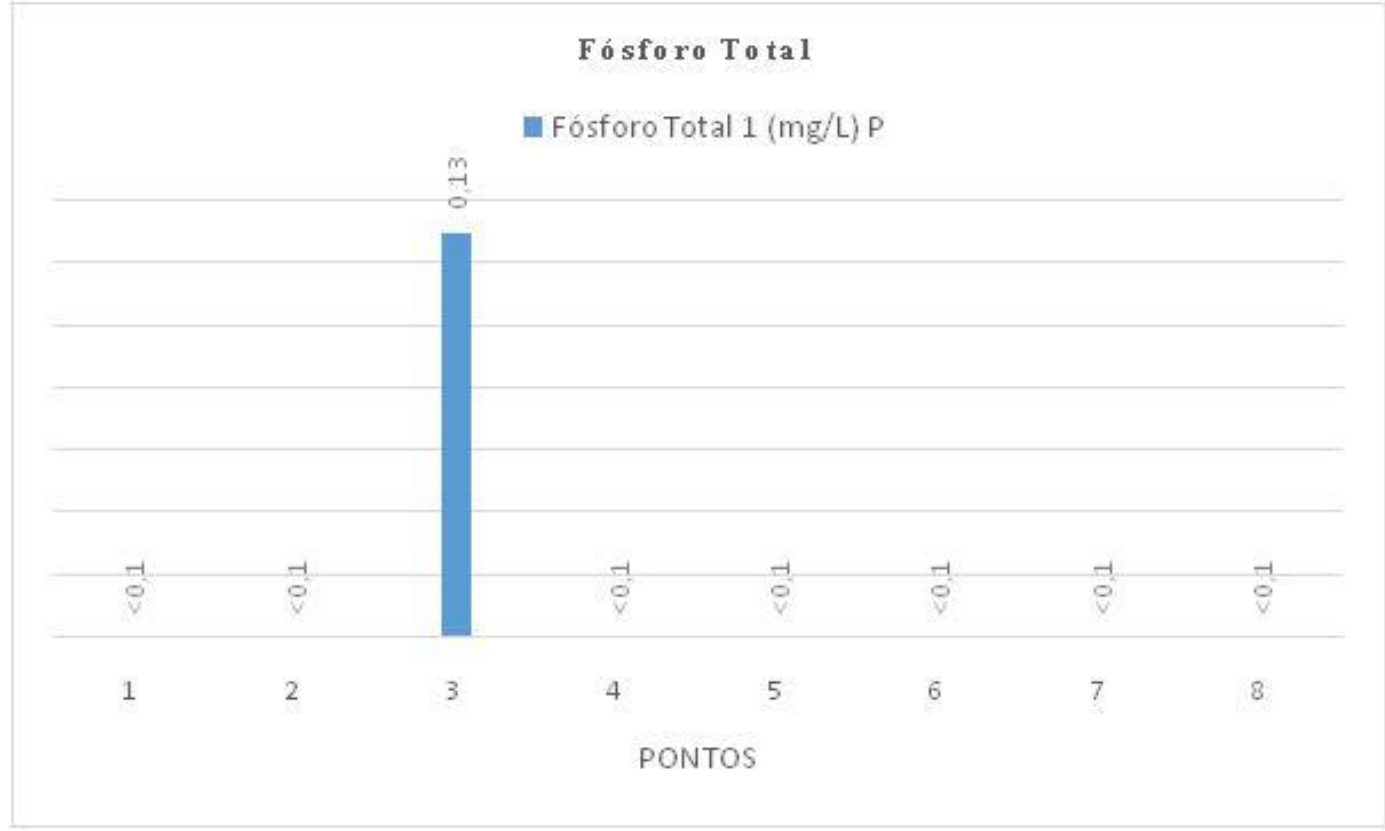

Fonte: Próprio autor. 
A Figura 11 apresenta os resultados de nitrogênio total para as duas campanhas. Verificase que os valores da segunda campanha não diferem muito da primeira. Provavelmente, os baixos valores encontrados para a concentração de oxigênio reduzido, principalmente nos pontos 2 e 5, podem ser devido ao consumo de oxigênio para a oxidação dos compostos nitrogenados, pois as concentrações de nitrogênio total nestes pontos foram altas.

O parâmetro nitrogênio total não apresenta limite máximo em nenhuma das legislações utilizadas neste estudo, entretanto, o mesmo foi determinado, pois é um dos parâmetros analisados para o cálculo do IQA.

Figura 11: Parâmetro Nitrogênio Total

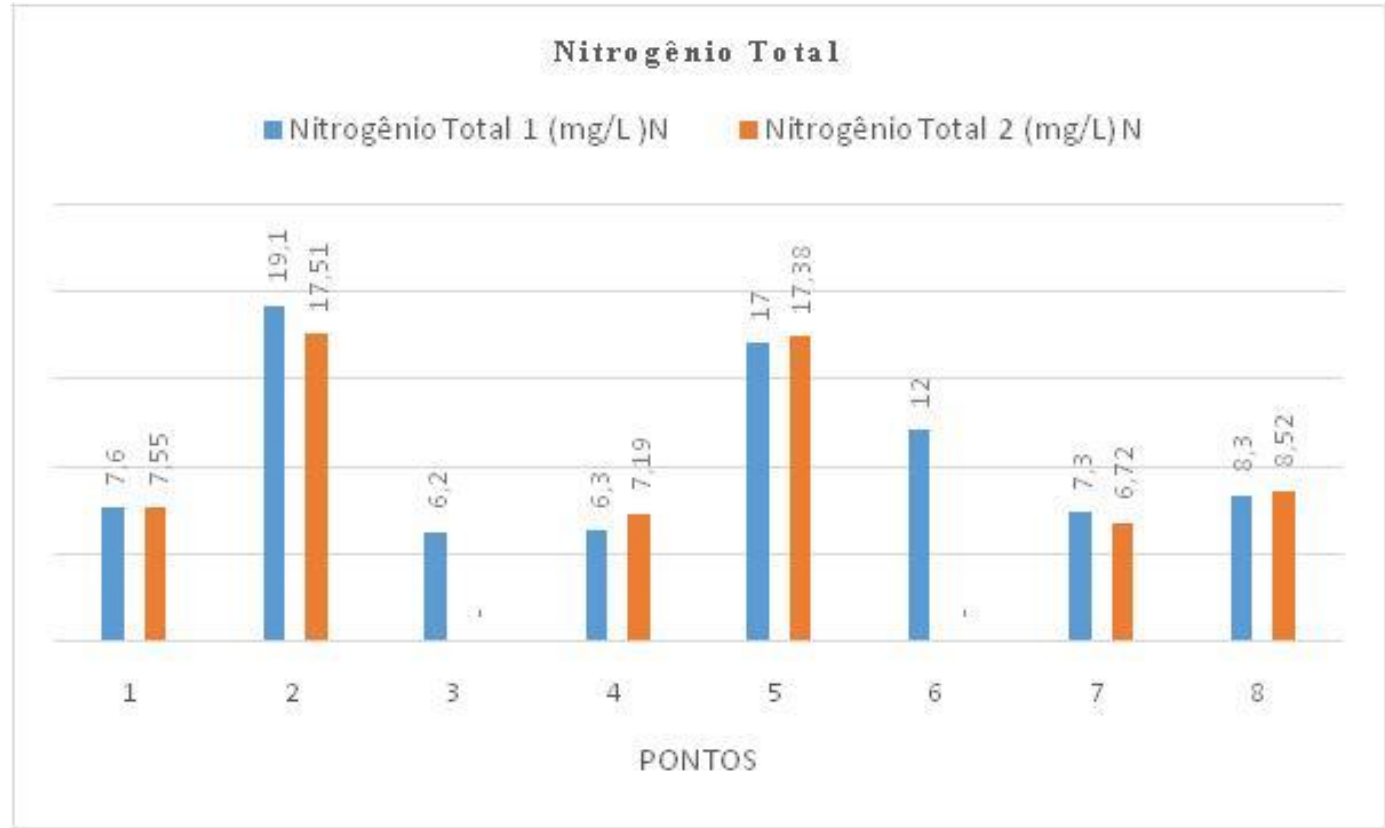

Fonte: Próprio autor.

\section{Resultados do IQA}

O índice de qualidade da água serve como um valor numérico para expressar sua qualidade, com base em medições físicas, químicas e biológicas (LUMB; SHARMA; BIBEAULT, 2011). A Tabela 2 expressa os resultados do IQA calculados para as duas campanhas (IQA 1 e IQA 2), empregando a planilha proposta por Von Sperling (2014). Após os cálculos, foi possível classificar a qualidade da água dos poços de acordo com o IQA - CETESB.

No ponto 5 , ao se colocar na planilha os valores de temperaturas de $26^{\circ} \mathrm{C}, 27^{\circ} \mathrm{C}$ e $28^{\circ} \mathrm{C}$, verificou-se que o resultado do IQA não se alterava. Desta forma, a temperatura média de $27^{\circ} \mathrm{C}$ foi considerada na análise do índice. Nos pontos 3 e 6 , não há resultado de cálculo de IQA pelos motivos já comentados anteriormente neste trabalho.

Verificando a Tabela 2, percebe-se que 0 IQA variou entre regular e bom nas duas campanhas. No período chuvoso, as águas coletadas nos pontos 2, 3, 4, 5 e 6 foram consideradas de boa qualidade (cor verde). No ponto 7, registrou-se o menor valor de IQA, em que a qualidade regular (cor amarela) deveu-se ao resultado dos coliformes termotolerantes, sendo determinante para este desempenho. Os pontos 1 e 8 também tiveram resultados regulares, mas ficaram próximos ao índice classificado como bom.

No período seco ocorreu uma inversão nos índices de qualidade. Os pontos 1, 7 e 8 , que tiveram classificação regular no período chuvoso, foram classificados como de boa qualidade, enquanto os pontos 2,4 e 5 , que tiveram classificação boa no período chuvoso, tiveram classificação regular neste período.

Os resultados indicam que, possivelmente, no período chuvoso, pode ter ocorrido uma diluição das concentrações com parâmetros determinados, exceto nos pontos 1,7 e 8 que, possivelmente, deve estar ocorrendo a percolação de efluentes domésticos, o que fez 
aumentar a concentração de DBO5 e coliformes termotolerantes.

A baixa pluviosidade no período seco, no momento em que foram coletadas as amostras, foi determinante para os resultados. Com a diminuição de recarga do aquífero, pode ter aumentado a concentração dos parâmetros determinados nos poços que foram considerados de boa qualidade no período chuvoso, o que fez reduzir o índice de qualidade para regular. Nos poços em que a qualidade foi considerada regular, com a diminuição da entrada de água no aquífero, provavelmente, se reduziu a contaminação por efluentes domésticos, o que fez melhorar o índice de qualidade.

Pode-se verificar que a pluviosidade tem bastante importância para a qualidade da água, visto que ocorreram mudanças significativas nos períodos chuvoso e seco.

Tabela 2: Resultados do IQA nos poços e classificação da água

\begin{tabular}{c|c|c}
\hline Ponto & IQA 1 & IQA 2 \\
\hline 1 & 50 & 56 \\
\hline 2 & 58 & 47 \\
\hline 3 & 64 & - \\
\hline 4 & 59 & 46 \\
\hline 5 & 55 & 49 \\
\hline 6 & 64 & - \\
\hline 7 & 37 & 61 \\
\hline 8 & 51 & 57 \\
\hline
\end{tabular}

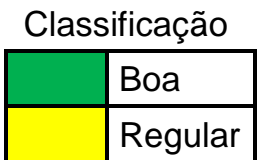

Fonte: Próprio autor.

\section{CONCLUSÃO}

Após análise dos resultados dos poços no bairro do Calabar, na cidade de Salvador-BA, e seu entorno, é possível concluir que os resultados do IQA mostraram águas com classificações variando entre regular e boa nos períodos chuvoso e seco, porém, não se pode concluir de fato se esta qualidade é significativa, pois somente foram realizadas duas campanhas.

É preciso ter cautela ao utilizar o IQA para determinar a qualidade da água, já que, analisando os parâmetros individualmente, alguns resultados não foram satisfatórios, ficando acima dos limites determinados pela Portaria de Consolidação № $05 / 17$ e pelas Resoluções CONAMA № 357/05 e 396/08 .

Diante disto, verifica-se que o valor de IQA pode ser por vezes mascarado por algum parâmetro que esteja com resultado considerado excelente.
Seria necessário um maior número de análises, a fim de traçar um perfil da variação da qualidade da água nos pontos amostrados, pois, como foi possível verificar, ocorrem mudanças nas concentrações dos parâmetros de acordo com o período temporal.

É necessário também estudar os outros parâmetros que determinam a potabilidade da água para consumo humano, de acordo com a Portaria de Consolidação № 05/17, principalmente os padrões organolépticos, como, por exemplo, dureza, gosto e odor, Escherichia Coli e alguns metais, haja vista que alguns moradores afirmam que bebem a água.

Como o tratamento da água possui um custo alto, já que se necessita de equipamentos específicos, e que são poços particulares em sua grande maioria, ou seja, os órgãos públicos não seriam responsáveis pelo tratamento, é adequado que se oriente a população sobre como utilizar a 
água dos poços no Calabar, evitando-se o seu consumo para beber ou, no mínimo, desinfetá-la, a fim de reduzirem-se os riscos de contaminação por microrganismos patogênicos.

\section{AGRADECIMENTOS}

Os autores agradecem à Universidade Federal da Bahia (UFBA) e ao Laboratório do Departamento de Engenharia Ambiental (LABDEA) pelo apoio na realização das análises das amostras de água.

\section{REFERÊNCIAS}

ABNT - ASSOCIAÇÃO BRASILEIRA DE NORMAS TÉCNICAS. NBR 12.244/2006: Construção de poço tubular para captação de água subterrânea. Disponível em:http://licenciadorambiental.com.br/wp-

content/uploads/2015/01/NBR-12.244-

Construc\%C3\%A3o-de-po\%C3\%A7o-para-

capta\%C3\%A7\%C3\%A3o-de-\%C3\%A1guasubterr\%C3\%A2nea.pdf. Acesso em: 13 jun. 2018.

ALABURDA, J.; NISHIHARA, L. Presença de compostos de nitrogênio em águas de poços. Revista Saúde Pública [online], v. 32, n. 2, p.160-165, 1998. ISSN 0034-8910. Disponível em: http://www.scielo.br/scielo.php?pid=S00348910199800 0200009\&script=sci abstract\&tlng=pt. Acesso: $01 \mathrm{dez}$. 2018.

ANA - AGÊNCIA NACIONAL DE ÁGUAS. Abastecimento Urbano de Água. 2010.

Disponível em:

http://atlas.ana.gov.br/Atlas/forms/analise/RegiaoMetro politana.aspx?rme=19. Acesso: 15 nov. 2018.

Índice de Qualidade das Águas (IQA).

Disponível em:

http://pnqa.ana.gov.br/indicadores-indice-aguas.aspx.

Acesso em: 15 nov. 2018.

ANIYIKAIYE, T. E.; OLUSEYI, T.; ODIYO, J. O.; EDOKPAYI, J. N.. Physico-chemical analysis of wastewater discharge from selected paint industries in Lagos, Nigeria. International Journal of Environmental Research and Public Health, v. 16, 7 ed., abr. 2019.

APHA. American Public Association. Standard Methods for the Examination of Water and Wastewater- 22th edition, 2012.

AVIGLIANO, E.; SCHENONE, N. Water quality in Atlantic rainforest montain rivers (South America): Quality indices assessment, nutrients distribution, and consumption effect. Environmental Science and Pollution Research, v. 23, ed. 15, p. 15063-15075, 2016.
BRASIL. Resolução CONAMA no 396, de 03 de Abril de 2008. Dispõe sobre a classificação e diretrizes para o enquadramento das águas subterrâneas, e dá outras providências. Diário Oficial da União de 07 de abril de 2008. Brasília, 2008. Disponível em:

http://www2.mma.gov.br/port/conama/legiabre.cfm?codl egi=562. Acesso em: 10 out. 2018.

Resolução CONAMA n 357 , de 17 de março de 2005. Dispõe sobre a classificação dos corpos de água para o seu enquadramento, bem como estabelece as condições e padrões de lançamento de efluentes, e dá outras providências. Diário Oficial da União de 17 de março de 2005. Brasília, 2005. Disponível em:

http://www2.mma.gov.br/port/conama/legiabre.cfm?codl egi=459. Acesso em: 13 set. 2018.

BUZELLI, G. M.; CUNHA-SANTINO, M.B. Diagnosis and analysis of water quality and trophic state of Barra Bonita Reservoir, SP. Revista Ambiente \& Água, v. 8, n. 1, p. 186-205, 2013.

CETESB. Qualidade das Águas Superficiais no Estado de São Paulo. Relatório. 2014. Disponível em: https://cetesb.sp.gov.br/aguas-interiores/publicacoes-erelatorios/. Acesso em: 01 dez. 2018.

Apêndice D. Índices de Qualidade das Águas. Disponível em:

https://cetesb.sp.gov.br/aguas-interiores/wpcontent/uploads/sites/12/2017/11/Ap\%C3\%AAndice-D\%C3\%8Dndices-de-Qualidade-das-\%C3\%81guas.pdf. Acesso em: 01 dez. 2018.

COSTA, A. B.; POSSELT, E. L.; MENEZES, C. M.; LOBO, E. A. Desenvolvimento e aplicação de Índices de Qualidade da Água. Revista do Departamento de Biologia da Universidade de Santa Cruz do Sul, v. 24, n. 1, 2012. Disponível em:

https://online.unisc.br/seer/index.php/cadpesquisa/articl e/view/4398. Acesso em: $01 \mathrm{dez} .2018$.

CHRISTOFOLETTI, S. R.; CONCEIÇÃO, F. T.; SPATTI JUNIOR, E. P. Relações hidroquímicas aplicadas à avaliação da qualidade da água na Bacia do Córrego Ibitinga, Rio Claro (SP). Revista Geociências, v. 34, n.2, 2015.

GUEZENNEC, A. G.; JOULIAN, C.; JACOB, J.; ARCHANE, A.; IBARRA, D.; BUYER, R.; BODENÁN, F.; D'HUGUES, P. Influence of dissolved oxygen on the bioleaching efficiency under oxygen enriched atmosphere. Minerals Engineering, v. 106, p.64-70, mai. 2017.

IBGE. Brasil em Síntese: Salvador. 2018.Disponível em: 
https://cidades.ibge.gov.br/brasil/ba/salvador/panorama . Acesso: 30 mai. 2018.

INMET. Chuva acumulada em Salvador. 2018. Disponível em:

http://www.inmet.gov.br/sim/abre graficos.php. Acesso em : 01 dez. 2018

LUMB, A.; SHARMA, T. C.; BIBEAULT, J. F. A review of genesis and evolution of water quality (WQI) and some future directions. Water Quality, Exposure and Health, v. 3, p. 11-24, 2011.

MMA - MINISTÉRIO DO MEIO AMBIENTE. Mananciais. 2018. Disponível em: http://www.mma.gov.br/cidadessustentaveis/aguasurbanas/mananciais.html. Acesso em: 09 set. 2019.

MINISTÉRIO DA SAÚDE. Portaria Unificada no 05 de 28 de setembro de 2017. Consolidação das normas sobre as ações e os serviços de saúde do Sistema Único de Saúde. Disponível em:

http://bvsms.saude.gov.br/bvs/saudelegis/gm/2017/prc0 $00503 \quad 10$ 2017.html. Acesso em: 15 nov. 2018.

OMS - ORGANIZAÇÃO MUNDIAL DA SAÚDE. Água. 2018. Disponível em:

http://www.who.int/es/news-room/fact-

sheets/detail/drinking-water. Acesso em: 24 nov. 2018.

ONU - ORGANIZAÇÕES DAS NAÇÕES UNIDAS. Escassez de Água. 2018.

Disponível em: http://www.unwater.org/waterfacts/scarcity/. Acesso em: 01 dez. 2018.

RODRÍGUEZ, M. S.; CRETTAZ-MINAGLIA, M. C.; GIANELLO, D.; PIAGGIO, M. Microbiological water quality of a temperate third- order stream. Rendiconti Lincei - Scienze Fische e Naturali, v. 30, v. 2, p. 417426, jun. 2019.
SANTOS, E.; PINHO, J. A. G.; MORAES, L. R. S.; FISCHER, T. (org.). O caminho das águas em Salvador. Bacias hidrográficas, bairros e fontes. Salvador: CIAGS/UFBA; SEMA, 2010.

SCHILLER, A. P.; FERRONATO, M.C.; SCHWANTES, D.; GONÇALVES JR, A.C.; BARILLI, D.J.; MANFRIN, $\mathrm{J}$. Influence of hydrological flows from tropical watersheds on the dynamics of $\mathrm{Cu}$ and $\mathrm{Zn}$ in sediments. Environmental Monitoring and Assessment, v. 19, 2. ed., p. 86, fev. 2019.

SILVA, T.T.; ESPÍRITO SANTO, K.S.; MATSUMOTO, S. T.; RIBEIRO, J. Monitoramento da qualidade da água da foz do Rio Santa Maria da Vitória e da Baía de Vitória - ES, por meio de estudos sistemáticos de parâmetros físicos, químicos e biológicos. Revista Virtual de Química, v. 10, n. 5, 2018.

SNIS - SERVIÇO NACIONAL DE INFORMAÇÕES SOBRE SANEAMENTO. Diagnóstico dos Serviços de Água e Esgotos. 2016. Disponível em: http://snis.gov.br/diagnostico-agua-e-

esgotos/diagnostico-ae-2016. Acesso em: 19 nov. 2018.

SIM - SISTEMA MUNICIPAL DE INFORMAÇÃO MUNICIPAL DE SALVADOR. Domicílio Particular Permanente Segundo Tipo de Abastecimento de Água. 2018. Disponível em: http://www.sim.salvador.ba.gov.br/indicadores/index.ph p. Acesso em: 12 out. 2018

VON SPERLING, M. Introdução à qualidade das águas e ao tratamento de esgotos. 4. ed. Belo Horizonte: Editora UFMG, 2014. V. 1.

ZHA, X.; MA, J.; LU, X.. Performance of a coupling device combined energy-efficient rotating biological contactors with anoxic filter for low-strength rural wastewater treatment. Journal of Cleaner Production, v. 196 , p. $1106-1115$, set. 2018. 